\title{
Use of existing data sources in clinical epidemiology: Finnish health care registers in Alzheimer's disease research - the Medication use among persons with Alzheimer's disease (MEDALZ-2005) study
}

This article was published in the following Dove Press journal:

Clinical Epidemiology

6 August 2013

Number of times this article has been viewed

\author{
Anna-Maija Tolppanen' \\ Heidi Taipale ${ }^{2,3}$ \\ Marjaana Koponen ${ }^{2,3}$ \\ Piia Lavikainen ${ }^{2}$ \\ Antti Tanskanen ${ }^{4,5}$ \\ Jari Tiihonen ${ }^{4-6}$ \\ Sirpa Hartikainen ${ }^{2,3}$ \\ 'Institute of Clinical Medicine - \\ Neurology, ${ }^{2}$ Kuopio Research \\ Centre of Geriatric Care, ${ }^{3}$ School \\ of Pharmacy, University of Eastern \\ Finland, Kuopio, Finland; ${ }^{4}$ Karolinska \\ Institutet, Department of Clinical \\ Neuroscience, Stockholm, Sweden; \\ ${ }^{5}$ National Institute for Health and \\ Welfare, Helsinki, Finland; 'University \\ of Eastern Finland, Department \\ of Forensic Psychiatry, Niuvanniemi \\ Hospital, Kuopio, Finland
}

\begin{abstract}
Memory diseases are the most important determinant of health care service use and quality of life among older individuals. Adverse effects of medication are common among older people, but this age group is underrepresented in clinical trials. Finnish statutory health care and prescription registers, together with personal identification numbers (PINs) and a tax-supported public health plan covering all citizens provide excellent opportunities for epidemiological research. We used routinely collected data from the Finnish health care system to establish the MEDication use among persons with ALZheimer's disease (MEDALZ-2005) cohort. This cohort study will be used to assess medication use and its effects on health status and hospitalization among persons with Alzheimer's disease (AD). The cohort includes all community-dwelling persons who had a clinically verified diagnosis of AD, resided in Finland, and were alive on December 31, 2005 and a matched comparison person for each affected individual. Data on purchased prescription medicines (1995-2009), inpatient hospital admissions (1972-2009), outpatient visits (1995-2009), details on diagnosed cancers (1972-2009), and mortality (until October 2010) are available for the whole cohort. This paper describes how this data can be utilized in etiological research and the assessment of health care service use, drug utilization, and associated adverse outcomes in a particularly vulnerable group that is often underrepresented in clinical trials.
\end{abstract}

Keywords: drug utilization, pharmacoepidemiology, epidemiology, cohort

\section{Background}

Worldwide, 35.6 million people were estimated to have dementia in 2010, with Alzheimer's disease (AD) being the most common form of dementia. ${ }^{1}$ The number of affected individuals is expected to rise to up to 115.4 million by 2050 due to changes in population structure. ${ }^{1}$ Cognitive decline and dementia are the most important determinants of health care service use: health care costs of AD or dementia patients are over three times higher than the costs of the aged population without these diseases. ${ }^{2}$ In the UK, the treatment of dementia costs more than treatments for cancer and cardiovascular diseases combined. ${ }^{3}$ In 2003, dementia contributed to $11.2 \%$ of all years lived with disability among those aged 60 years or older, which is more than the contributions of cancer, cardiovascular diseases, musculoskeletal disorders, or stroke. ${ }^{4}$

Immense research effort has focused on modifiable risk factors and disease-modifying or -delaying therapies for AD. However, the therapeutic advances have been modest,
Correspondence: Anna-Maija Tolppanen University of Eastern Finland, Institute of Clinical Medicine - Neurology, PO Box 1627, FIN 702II Kuopio, Finland Tel +358403552015

Fax $+35817 \quad 162048$

Email anna-maija.tolppanen@uef.fi 
and only symptomatic treatment with acetylcholinesterase inhibitors and/or memantine is available. In addition, behavioral and psychological symptoms, eg, agitation, depression, apathy, delusions, hallucinations, and sleep disturbances are often treated with psychotropic drugs, such as antidepressants or antipsychotics, although evidence on the benefits of these treatments is inconsistent. ${ }^{5}$ Further, aging leads to several pharmacokinetic and pharmacodynamic changes. ${ }^{6,7}$ Thus, the results from randomized controlled trials of psychotropic drugs with more restricted selections of patients are not likely to be generalizable to the actual user population. ${ }^{8}$ In addition, the sample sizes needed to detect less common adverse effects would be unfeasibly large for randomized controlled trials and, thus, large population-based studies are needed to provide data on the effectiveness and possible adverse events related to medications in the actual user population. Persons with $\mathrm{AD}$ are a particularly vulnerable group, and thus it is important to assess whether the risk-benefit profile, estimated in trials that have often excluded aged individuals, those with cognitive impairment, multiple comorbidities or concomitant medications, is directly applicable.

Finnish statutory health care and prescription registers, together with personal identification numbers (PINs) provide excellent opportunities for epidemiological research. Similar systems are used in other Nordic countries, but, in Finland and Denmark, the data are available from a longer period of time than in other Nordic countries (a national prescription register was introduced in 1994 in Finland and Denmark, but in 2004-2006 in other Nordic countries, ${ }^{9}$ while hospital discharge data is available from 1967 in Finland and from 1977 in Denmark $^{10}$ ). However, changes in Finnish PINs in the 1970s means that reliable automated linkage without individual checking and recoding of PINs is possible with data from 1972 onwards. Finland (population 5.4 million, gross domestic product $€ 178,796$ million in 2010 ) has a similar population structure to other developed countries: in 2012, $18.8 \%$ of the population was 65 years or older, and this percentage is expected to increase up to $26.9 \%$ by $2050 .{ }^{11}$ For those born in 2011, life expectancy was 83.5 years for girls and 77.2 years for boys. All citizens/residents are covered by a tax-supported public healthcare plan and have unrestricted access to health services, independent of socioeconomic status. ${ }^{9}$ Public health care, provided by municipalities, is organized according to a national framework, set by the Ministry of Social Affairs and Health. In addition to the public health care system, health care services are available from private providers.

The MEDication use among persons with ALZheimer's disease (MEDALZ-2005) cohort was set up to investigate medication use and health statuses of persons with Alzheimer's disease on a nationwide level. The aim of this paper is to describe (1) how this routinely collected data from health care registers can be utilized in clinical epidemiology, and (2) the baseline characteristics of the MEDALZ-2005 population.

\section{Methods of the MEDALZ-2005 study Study design}

Our sample consists of two closed cohorts: (1) all 28,093 persons with a verified diagnosis of $\mathrm{AD}$ residing in Finland (population 5.3 million, 97.8\% Finnish citizens and 2.2\% noncitizens) on December 31, 2005; ${ }^{12}$ and (2) their matched comparison group with no diagnosed AD. To be included in the sample, the participants needed to be (1) alive on 31 December, 2005, and (2) community-dwelling. Therefore, our sample does not include persons who were living in institutionalized settings at the beginning of the study.

Persons with AD were identified from the Special Reimbursement Register ${ }^{13}$ and a single comparison person matched for age ( \pm 1 year), sex, and region of residence (on the basis of university hospital district) per AD case was identified from the Finnish Social Insurance Institution (SII) database, including all residents of Finland with a PIN, ie, all citizens and residents living in Finland for at least 2 years, but not those citizens who had been living abroad for more than 1 year.

Altogether, 145 comparison persons had temporarily been entitled to reimbursed AD medication before 2006 and these persons, together with their matched pairs, have been excluded from the analyses. Altogether 2,015 persons converted to AD during 2006-2009, and we have therefore modelled AD as a time-dependent variable in the prospective studies. Due to the advanced age of the population, it is likely that some of the participants were institutionalized during the follow-up, beginning on January 1, 2006.

Some public nursing homes provide residents' medications and, for pharmacoepidemiological studies, it is no longer possible to reliably assess medication exposure from the prescription register after institutionalization. Thus, for pharmacoepidemiological studies, persons are censored at the date of institutionalization to facilities providing medication based on the date recorded in a special register maintained by the SII. Hospitalizations, together with diagnoses and operations, are still recorded in the hospital discharge register after institutionalization, so these persons can be included in studies assessing health status. 


\section{Diagnosis of $A D$}

The Finnish special reimbursement register contains information on reimbursement due to specific chronic diseases such as diabetes, cardiovascular diseases, and Alzheimer's disease. As per national guidelines for $\mathrm{AD}$ treatment, ${ }^{15}$ this register allows identification of every person with clinically diagnosed $\mathrm{AD}$, regardless of whether they purchased the $\mathrm{AD}$ medication after being diagnosed. We are not aware of this kind of nationwide register with longitudinal data elsewhere, although Sweden recently set up the Swedish Dementia Registry (SveDem), including 6,937 dementia patients diagnosed during 2007-2009. ${ }^{14}$

The Finnish Current Care Guidelines recommend that all persons with $\mathrm{AD}$ are treated with acetylcholinesterase inhibitors or with memantine unless there is a specific contraindication. ${ }^{15}$ To be eligible for reimbursed AD medication, the patient needs to have a verified diagnosis of $\mathrm{AD}$ described in a medical statement submitted to the SII by a physician. The medical statement must state that the patient has: (1) symptoms consistent with $\mathrm{AD}$; (2) experienced a decrease in social capacity over a period of at least 3 months; (3) received a computed tomography/magnetic resonance imaging scan; (4) had possible alternative diagnoses excluded; and (5) received confirmation of the diagnosis by a registered neurologist or geriatrician. ${ }^{15} \mathrm{AD}$ is diagnosed according to the National Institute of Neurological and Communicative Disorders and Stroke and the Alzheimer's Disease and Related Disorders Association (NINCDS-ADRDA [now known as the Alzheimer's Association]) and The Diagnostic and Statistical Manual of Mental Disorders (DSM)-IV criteria for Alzheimer's disease. ${ }^{16,17}$ The physician also needs to confirm whether the patient has other dementing diseases, such as multi-infarct dementia or Lewy body dementia. However, patients with these diseases are also entitled to reimbursed medicines if the symptoms are considered to be mainly caused by AD. ${ }^{18}$

The special reimbursements for acetylcholinesterase inhibitors and memantine were introduced in 1999 and 2003, respectively, and the diagnostic criteria have been consistent. In the beginning, the reimbursement decisions were often made on a temporary basis, but permanent decisions were introduced in July 2003. Earlier, only patients with mild or moderate $\mathrm{AD}$ were entitled to reimbursed anti-dementia medication, but the reimbursement was not withdrawn if/ when the patient developed severe AD. People with severe $\mathrm{AD}$ have been entitled to reimbursed $\mathrm{AD}$ medication since 2003. Thus, our study sample includes persons with all stages of AD. Data on severity or stage of Alzheimer's disease is not available from the registers, but the diagnosis date from the special reimbursement register can be used as a crude estimate on mild/moderate stages of AD. The Finnish public health system covers all residents regardless of age or income. Thus, one of the strengths of our cohort is that, unlike cohorts consisting of members of a particular private health care insurance scheme, MEDALZ-2005 is not selected on the basis of socioeconomic position.

\section{Data sources and variables collected}

The data resource formation is described in Figure 1 and data provided by the individual registers are summarized in Table 1. The hospital discharge database includes all medical services and procedures billed on a fee-for-service basis, whether rendered in an outpatient, inpatient, or emergency department setting. Public health care service use is accurately described in these registers, as this is mandated by legislation. However, the same pressure does not apply to private health care providers. Thus, the accuracy of hospital discharge data depends on how much the study population utilizes private services. The mean age of our sample was 80.6 years and persons belonging to this age group almost exclusively use the services of the statutory health care system, ${ }^{19}$ the hospital discharge register is representative of their health care service use. The hospital discharge register data were preprocessed, so we have the exact hospitalization periods, diagnoses, performed procedures, and cost per hospitalization period for each participant. The costs are calculated according to Finnish health care system unit costs. ${ }^{20}$ Diagnoses for each admission are made by the attending physician.

Data on all reimbursed purchased prescription medicines, emollient creams, and clinical nutrients, regardless of the setting in which they were prescribed, are recorded in the prescription register. Over-the-counter medications and medicines used in the hospitals are not recorded in the register. Prescription data are converted to medication periods with start date, length, average dosage, and cost. The method of calculating medication-use periods from prescriptions is developed from previously used methods. ${ }^{21-23}$

The cancer register, ${ }^{24}$ maintained by the Finnish Cancer Registry, is a continuously updated nationwide database on all primary cancers in Finland. Final coding is done by qualified secretaries and supervised by the Registry physician (a pathologist). Reporting of cancers has been mandated by law since 1961 (see Table 1 for a detailed description of the contents of this register). In addition, we have data on discharges from social institutions as well as causes of death (Table 1). 


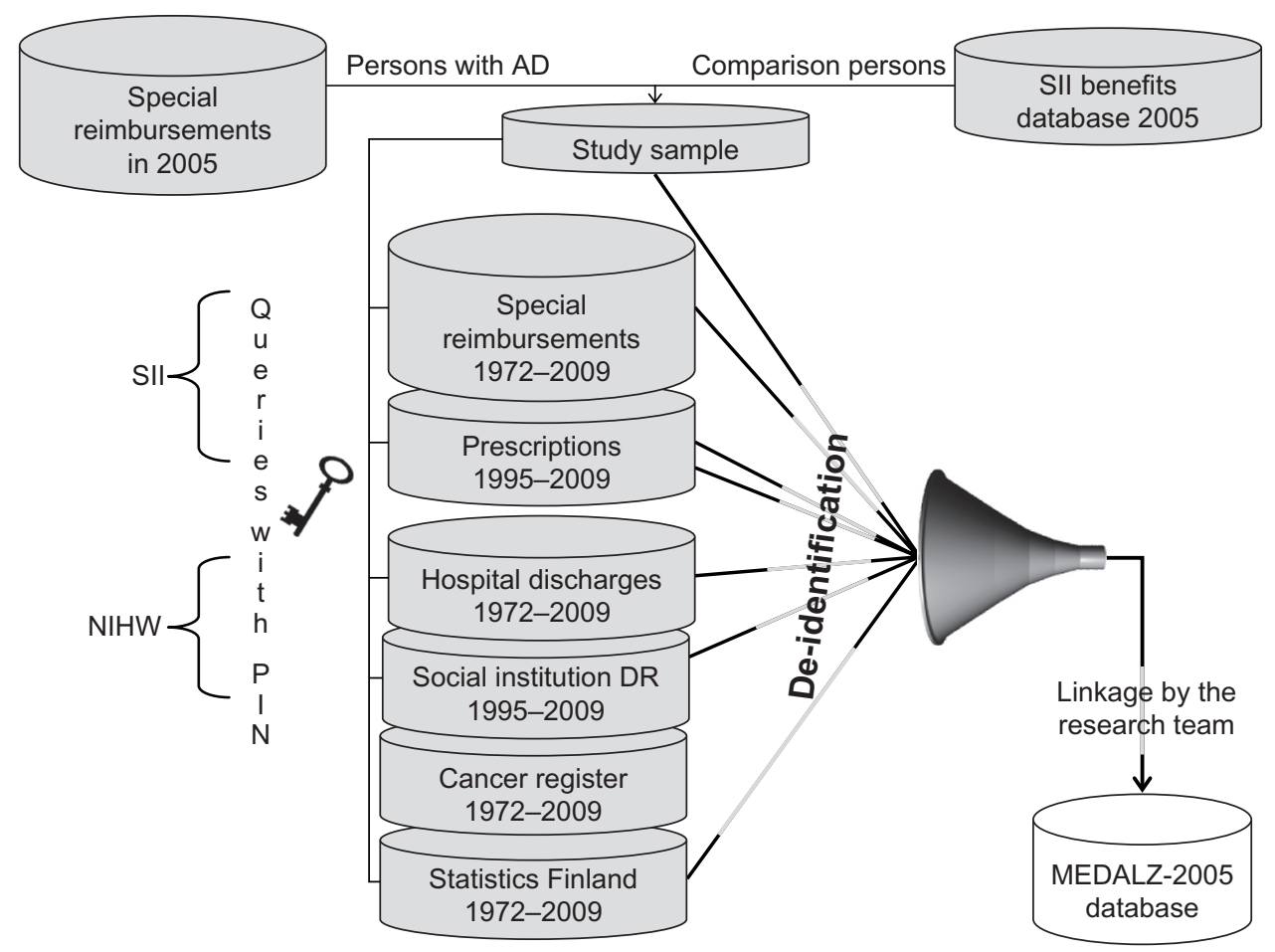

Figure I Cohort formation.

Notes: The participants were identified from the special reimbursement register and SIl benefits database of 2005 and the data from separate registers were retrieved by the register maintainers.

Abbreviations: AD, Alzheimer's disease; DR, discharge register; MEDALZ-2005, MEDication use among persons with ALZheimer's disease; NIHW, National Institute of Health and Welfare; PIN, personal identification number; SII, Social Insurance Institution.

Table I MEDALZ-2005 data sources and their contents

\begin{tabular}{|c|c|}
\hline Register & Data provided \\
\hline Prescription register ${ }^{9}$ & $\begin{array}{l}\text { All reimbursed medicines, emollient cream, and clinical nutrients purchased by the individual. Medicines } \\
\text { used in hospitals are not included, but the register covers prescriptions written by hospital physicians and } \\
\text { dispensed in community settings. For each medicine, the prescription register contains data on dispensing } \\
\text { date, number of packages/tablets, strength of the medicine, defined daily dose, and cost of medication. }\end{array}$ \\
\hline Reimbursement register ${ }^{13}$ & $\begin{array}{l}\text { Entitlement to special reimbursement due to severe chronic diseases such as Alzheimer's disease, diabetes, } \\
\text { psychosis, epilepsy, glaucoma, rheumatic conditions, asthma, chronic obstructive pulmonary disease, } \\
\text { hypothyreosis and several cardiovascular diseases, including cardiac insufficiency, chronic hypertension, } \\
\text { and chronic ischemic heart diseases. To be included in the Special Reimbursement Register, the diagnosis } \\
\text { must be based on explicit predefined criteria and written documentary evidence, including results of } \\
\text { diagnostic tests such as imaging or blood biochemistry, which must be provided to the Sll by a physician. }\end{array}$ \\
\hline Hospital discharge register ${ }^{53}$ & $\begin{array}{l}\text { Use of in- and outpatient health care services. The diagnoses for each admission are made by the attending } \\
\text { physician. The register contains the following information on each hospital visit: dates; reason for hospital } \\
\text { stay (up to six ICD codes per visit; versions ICD8, 9, and I0); specialty of the caring unit; date of surgery; } \\
\text { up to five operational codes (NOMESCO classification); where the patient was discharged to; and an } \\
\text { assessment of need for assistance in activities of daily life. In addition, for patients admitted to a psychiatric } \\
\text { unit, data are available on whether treatment was involuntary, duration of involuntary treatment, recurrence } \\
\text { of visits to the psychiatric unit, and use of restrictive methods. }\end{array}$ \\
\hline $\begin{array}{l}\text { Discharge register from social } \\
\text { institutions }{ }^{25}\end{array}$ & $\begin{array}{l}\text { Home care and care in social service institutions, including dates, reason for admission, status of } \\
\text { independence when discharged, and where the client was discharged to. }\end{array}$ \\
\hline Cancer register ${ }^{24}$ & $\begin{array}{l}\text { All malignant neoplasms, carcinoid tumors, carcinoma in situ lesions (except those of the skin), cervical } \\
\text { intraepithelial neoplasia grade III, histologically benign tumors of the central nervous system and meninges, } \\
\text { transitional cell papillomas of the urinary tract, and ovarian tumors with borderline malignancy. Each cancer } \\
\text { considered to be an independent new primary lesion is registered separately and all independent cancer } \\
\text { processes are coded as separate entities. Data on diagnosis date, primary site, basis of diagnosis, localization } \\
\text { stage, malignancy, histology/cell type, treatment details, and survival are included. }\end{array}$ \\
\hline Statistics Finland" & Causes of death. \\
\hline
\end{tabular}

Abbreviations: ICD, International Classification of Diseases; NOMESCO, Nordic Medico-Statistical Committee; SII, Social Insurance Institution; MEDALZ-2005, MEDication use among persons with ALZheimer's disease. 
Mortality data were obtained from the SII. The SII registers are updated daily with mortality data using the Population Information System maintained by the Population Register Centre of Finland. Data include each participant's exact date of death.

\section{Follow-up}

Retrospective data from 1972 to 2005 are available. The individual-level data in Finnish health care registers are continuously updated. Currently, we have prospective data on hospital discharges, cancer register, prescriptions, and social institution discharges until 2009 and mortality data until September 2010. We are updating the database with data from 2009-2012 in 2013.

\section{Research questions in the MEDALZ- 2005 cohort}

We are investigating four different research lines: (1) medication use, its persistence, and changes during follow-up; (2) health-related risk factors for AD and clinically important changes in health status after $\mathrm{AD}$ diagnosis; (3) medication use and its associations with adverse outcomes (mortality, hip fractures, gastrointestinal bleeds, and cardio- and cerebrovascular events) in persons with $\mathrm{AD}$; and (4) use of social and health care services.

\section{Results \\ Baseline characteristics of the study population}

The baseline status of the cohort is described in Table 2 . Persons with AD were somewhat more likely to have epilepsy or medically treated diabetes and less likely to have cardiovascular diseases or cancer, although the absolute differences in prevalence were small. The majority (over $60 \%$ ) of AD cases were diagnosed in 2003-2005, with over a quarter $(25.8 \%)$ being diagnosed in 2005 . The earliest diagnoses were from 1999.

\section{Medication use}

In cross-sectional analyses of the 2005 data (Table 2), we found that antipsychotic use was nearly six times more common among community-dwelling persons with $\mathrm{AD}$ (22.1\%) in comparison to the matched population with no $\mathrm{AD}(4.4 \%)$, and that most antipsychotics were prescribed by primary care physicians ${ }^{26}$ Further, use of older antiepileptic medicines (phenytoin, clonazepam, valproic acid, and oxcarbazepine) was more prevalent among persons with $\mathrm{AD},{ }^{27}$ although these persons are particularly vulnerable
Table 2 Description of the study population at baseline (December 31, 2005)

\begin{tabular}{|c|c|c|}
\hline & $\begin{array}{l}\text { AD group } \\
n=27,948\end{array}$ & $\begin{array}{l}\text { Non-AD } \\
\text { group } \\
n=27,948\end{array}$ \\
\hline Age in 2005 , years & $80.6(6.8)$ & $80.6(6.8)$ \\
\hline \multicolumn{3}{|l|}{ Sex } \\
\hline Men & $9,014(32.3)$ & $9,014(32.3)$ \\
\hline Women & I8,934 (67.7) & $18,934(67.7)$ \\
\hline \multicolumn{3}{|l|}{ History of comorbidities } \\
\hline Cardiovascular disease & I4, I94 (50.80) & $14,544(52.0)$ \\
\hline Diabetes & $3,355(12.0)$ & $2,993(10.7)$ \\
\hline $\begin{array}{l}\text { Asthma/chronic obstructive } \\
\text { pulmonary disease }\end{array}$ & $2,045(7.3)$ & $2,404(8.6)$ \\
\hline Epilepsy & $577(2.1)$ & $35 \mathrm{I}(\mathrm{I} .3)$ \\
\hline \multicolumn{3}{|c|}{ Modified Charlson comorbidity index ${ }^{\mathrm{a}}$} \\
\hline 0 & I6,075 (57.5) & $16,152(57.8)$ \\
\hline I & $7,575(27.1)$ & $7,678(27.5)$ \\
\hline 2 & 3,177 (II.4) & $3,103(11.1)$ \\
\hline$\geq 3$ & $I,|2|(4.0)$ & $1,015(3.6)$ \\
\hline \multicolumn{3}{|l|}{ Year of AD diagnosis } \\
\hline 1999 & $724(2.6)$ & NA \\
\hline 2000 & $\mathrm{I}, \mathrm{I} 46(4 . \mathrm{I})$ & NA \\
\hline 2001 & $2,010(7.2)$ & NA \\
\hline 2002 & $3,302(11.8)$ & NA \\
\hline 2003 & $5,904(21.1)$ & NA \\
\hline 2004 & $7,678(27.5)$ & NA \\
\hline 2005 & $7,184(25.8)$ & NA \\
\hline \multicolumn{3}{|l|}{ Medication use in 2005} \\
\hline $\begin{array}{l}\text { Any antipsychotic } \\
\text { (ATC code N05A) }\end{array}$ & $6,167(22.1)$ & $1,216(4.4)$ \\
\hline $\begin{array}{l}\text { Anti-dementia medications } \\
\text { (ATC code N06D) }\end{array}$ & $23,979(85.8)$ & 0 \\
\hline $\begin{array}{l}\text { Any antiepileptic medication } \\
\text { (ATC code N03A) }\end{array}$ & $\mathrm{I}, 4 \mid 2(5.1)$ & $953(3.4)$ \\
\hline Any opioids (ATC code N02A) & $997(3.6)$ & $|, 29|(4.6)$ \\
\hline
\end{tabular}

Notes: Data are given as mean (SD) for age and $\mathrm{n}(\%)$ for categorical variables. Those 145 persons without $A D$ who had temporarily been entitled to reimbursed $A D$ medication before 2006, together with their matched pair, are excluded. alncludes the following diseases with corresponding scores: heart failure; coronary artery disease; type I or 2 diabetes; chronic asthma or chronic obstructive pulmonary disease; disseminated connective tissue diseases; rheumatoid arthritis and other comparable conditions (score of I); uremia requiring dialysis; severe anemia in connection with chronic renal failure; and leukemia or other malignant diseases of blood and bone marrow including malignant diseases of the lymphatic system and all cancers (score of 2).

Abbreviations: AD, Alzheimer's disease; ATC, Anatomical Therapeutic Chemical; SD, standard deviation.

to adverse events associated with these medicines. ${ }^{28} \mathrm{We}$ also found that use of opioids was less common in persons with $\mathrm{AD}$, which highlights the challenges associated with diagnosing and treating pain in this population. Clinical manifestations of pain in older adults are often complex and multifactorial and the symptoms may be underreported by the patient, which may lead to undertreatment of pain. ${ }^{29}$ In our study, the differences were mainly due to lower use of tramadol in people with AD. Tramadol is considered to have anticholinergic activity and it may interact with 
acetylcholinesterase inhibitors, ${ }^{30}$ which may lead to limited tramadol prescribing in persons with AD. Persons with AD may also be particularly susceptible to opioid-related adverse drug events, such as delirium, ${ }^{31,32}$ which can lead to avoidance of opioids. However, strong opioids and transdermal fentanyl patches were more commonly used among persons with AD in our study. ${ }^{33}$

\section{Health status and mortality during follow-up}

On average, persons with $\mathrm{AD}$ were twice as likely to die during the follow-up in comparison to the matched population. ${ }^{34}$ The risk difference was more pronounced at younger ages $(<80$ years old) and even a short duration of $\mathrm{AD}$ ( $\leq 3$ years) was associated with a significantly increased risk of death. The association persisted after adjusting for comorbidities, suggesting that AD has an important and independent impact on mortality. Altogether, 18,395 (32.7\%) persons (11,726 and 6,669 with and without AD, respectively) died during 2006-2009. ${ }^{34}$ Persons who died during follow-up were a mean age of 3.8 years older and were more likely to be men and have Alzheimer's disease and other chronic comorbidities (Table 3). Longer duration of $\mathrm{AD}$ was also related to higher mortality.

Our further analyses of prospective data showed that persons with AD had more incident hemorrhagic strokes than the age-matched population without AD, although there were no differences in the incidence of ischemic strokes. ${ }^{35}$ We also assessed the association between AD and incident hip fracture. ${ }^{36}$ Although there was some evidence of effect modification by age and sex, AD was consistently associated with a doubling of the risk of incident hip fracture. The overall risk estimate was similar to that of previous observational studies, ${ }^{37-41}$ supporting the reliability and external validity of our data. The cohort contains persons with variable durations of AD, which may have affected the results. To address the extent of bias introduced by different disease duration, we performed sensitivity analyses including only those $\mathrm{AD}$ patients who were diagnosed in 2004-2005. This had no effect on the conclusions of our studies.

\section{Retrospective analyses}

In addition to prospective analyses, the study design allows retrospective analyses for possible AD risk factors. Diabetes requiring medical treatment, especially if diagnosed in midlife, was associated with higher risk of AD in the MEDALZ-2005 cohort. ${ }^{42}$ The estimates were in agreement with
Table 3 Differences between MEDALZ-2005 participants who died during 2006-2009 and survivors

\begin{tabular}{|c|c|c|}
\hline & $\begin{array}{l}\text { Alive in } 2009 \\
n=37,639\end{array}$ & $\begin{array}{l}\text { Died during } \\
2006-2009 \\
n=18,257\end{array}$ \\
\hline Age in 2005 , years & $79.4(6.7)$ & $83.2(6.3)$ \\
\hline \multicolumn{3}{|l|}{ Sex } \\
\hline Men & $\mathrm{II}, \mathrm{I} 40(29.6)[6 \mathrm{I} .8]$ & $6,888(37.7)[38.2]$ \\
\hline Women & $26,499(70.4)[70.0]$ & II,369 (62.3) [30.0] \\
\hline$A D$ & $16,280(43.3)[58.3]$ & $11,668(63.9)[41.7]$ \\
\hline Cardiovascular disease & $18,106(48.1)[63.0]$ & $10,632(58.2)[37.0]$ \\
\hline Diabetes & $3,696(9.8)[58.2]$ & $2,652(\mid 4.5)[4 \mid .8]$ \\
\hline $\begin{array}{l}\text { Asthma/chronic } \\
\text { obstructive pulmonary } \\
\text { disease }\end{array}$ & $2,884(7.7)[64.8]$ & $\mathrm{I}, 565(8.6)[35.2]$ \\
\hline Epilepsy & $533(1.4)[57.4]$ & $395(2.2)[42.6]$ \\
\hline \multicolumn{3}{|l|}{ Year of AD diagnosis } \\
\hline 1999 & $37 \mid(2.28)[5 I .2]$ & $353(3.0)[48.8]$ \\
\hline 2000 & $622(3.8)[54.3]$ & $524(4.5)[45.7]$ \\
\hline 2001 & $1,096(6.7)[54.5]$ & $914(7.8)[45.5]$ \\
\hline 2002 & $\mathrm{I}, 837(\mathrm{I} I .3)[55.6]$ & $1,465(12.6)[44.4]$ \\
\hline 2003 & $3,373(20.7)[57.1]$ & $2,531(21.7)[42.9]$ \\
\hline 2004 & $4,456(27.4)[58.0]$ & $3,222(27.6)[42.0]$ \\
\hline 2005 & $4,525(27.8)[63.0]$ & $2,659(22.8)[37.0]$ \\
\hline \multicolumn{3}{|c|}{ Modified Charlson comorbidity index ${ }^{\mathrm{a}}$} \\
\hline 0 & $23,289(61.9)[72.3]$ & $8,938(49.0)[27.7]$ \\
\hline I & $9,790(26.0)[64.2]$ & $5,463(29.9)[35.8]$ \\
\hline 2 & 3,517 (9.3) [56.0] & $2,763(I 5.1)[44.0]$ \\
\hline$\geq 3$ & $\mathrm{I}, 043(2.8)[48.8]$ & $\mathrm{I}, 093(6.0)[5 \mathrm{I} .2]$ \\
\hline
\end{tabular}

Notes: Data are given as mean (SD) for continuous variables and $n$ (column percentage) [row percentage] for categorical variables. Those 145 persons without AD who had temporarily been entitled to reimbursed AD medication before 2006 , together with their matched pair, are excluded. alncludes the following diseases with corresponding scores: heart failure; coronary artery disease; type I or 2 diabetes; chronic asthma or chronic obstructive pulmonary disease; disseminated connective tissue diseases; rheumatoid arthritis and other comparable conditions (score of I); uremia requiring dialysis; severe anemia in connection with chronic renal failure; and leukemia or other malignant diseases of blood and bone marrow including malignant diseases of the lymphatic system and all cancers (score of 2).

Abbreviations: AD, Alzheimer's disease; MEDALZ-2005, MEDication use among persons with ALZheimer's disease; SD, standard deviation.

a previous meta-analysis from carefully phenotyped cohort studies. $^{43}$

\section{Discussion}

We have described how routinely collected health care data can be utilized in clinical epidemiology research to assess potential risk factors for $\mathrm{AD}$, describe differences in health status after AD diagnosis, and assess drug utilization in a nationwide sample. We have also shown that our findings are similar to those that have been reported in previous cohort studies and meta-analyses, ${ }^{37-41,43}$ supporting the external validity of our cohort. Our future plans are to assess the possible benefits and/or adverse outcomes related to medication use and compare the health care service use patterns between the $\mathrm{AD}$ and non-AD cohorts. 


\section{Strengths and weaknesses of this approach}

The main prerequisite for using register-based data is the quality of the data, ie, the data need to have good coverage and validity. Studies assessing internal validity of Finnish administrative registers ${ }^{44}$ and comparing register information with patient records or other information from the primary source have confirmed that the coverage and accuracy of Finnish register data are well-suited for epidemiological research. ${ }^{45-53}$ However, the prevalence of AD is underestimated in the registers, especially in the earlier data, because only those persons seeking medical attention will be included. On the other hand, according to the Finnish Statistics on Medicines,,${ }^{11}$ the number of new AD diagnoses per year has increased, suggesting a better implementation of $\mathrm{AD}$ diagnosis by heath care professionals. Another limitation is the lack of data on the severity of AD. On the other hand, due to explicit diagnostic criteria, positive predictive value, the $\mathrm{AD}$ diagnosis is high. Some other chronic diseases, such as chronic obstructive pulmonary disease (COPD), will be underrepresented, as only the most severe cases will be captured while untreated and undiagnosed cases will be missing from the registers. Thus, the findings will be representative of the severe forms of, in this example, COPD and not necessarily generalizable to those with milder forms of the disease.

The main limitation of register-based data, which is not specific to our study, is the lack of information on genetic or lifestyle-related confounders, such as body composition and smoking or alcohol use. The latter variables are difficult to measure accurately in epidemiological studies in general, especially without biomarkers. We have access to complete medical histories of the cohort members from 1972 onwards, which can be used as a proxy measure for these confounders, eg, by constructing a comorbidity index (Tables 2 and 3 ). We also have data on health service use due to substance abuse, although this will likely capture only the most severe cases. Further, we currently lack the socioeconomic information for the cohort (eg, education, marital status, income), although we are planning to obtain this from Statistics Finland in future.

The prescription register does not include over-thecounter medicines or medication used in hospitals or nursing homes. ${ }^{9}$ Further, only reimbursed medicines are recorded in the prescription register. It should also be noted that the prescription register contains only the dates of purchases and amount of purchased medications, which may not accurately represent the actual drug use. However, the validity of the prescription register in comparison with self-reported medication use has been confirmed. ${ }^{54,55}$ Further, the available information allows us to estimate use periods for each drug/drug group. This will provide more detailed estimation of the actual exposure period than a crude yes/no variable. Our data are well-suited for drug utilization and pharmacoepidemiological research. We have thorough records, with approximately 40 years of medical data and 15 years of prescription data, of all community-dwelling persons with a verified diagnosis of AD residing in Finland. To our knowledge, similar longitudinal nationwide data does not exist elsewhere in the world. Thus, this project provides a unique opportunity to investigate the medication use and health status in a vulnerable population whose size will increase drastically in upcoming years.

\section{Data access}

MEDALZ-2005 is a complex dataset and, although deidentified, the database includes sensitive personal information from over 50,000 individuals. We welcome suggestions for collaboration and note that we have agreed to comply with the regulations of database maintainers, ie, SII, National Institute of Health and Welfare, and Cancer Registry, all of which limit the use of data to strictly noncommercial purposes and restrict the data access to only those persons who are entitled to have access to the data according to accepted research proposals. Thus, new permissions for each individual accessing the data need to be filed. In addition, data provided by the National Institute of Health and Welfare, such as information on hospital discharges and social service use, cannot be sent abroad.

\section{Conclusion}

These routinely collected data enable the identification of all individuals with a clinically verified diagnosis of $A D$ as well as the assessment of their medication and health care service use. Register-based studies provide a feasible way for assessing medication use and associated outcomes in population groups that are underrepresented in randomized controlled trials.

\section{Acknowledgment}

We are grateful to the maintainers and data managers of Finnish health care registers for enabling this research effort.

\section{Disclosure}

The authors report no conflicts of interest in this work. 


\section{References}

1. World Health Organization, Alzheimer's Disease International. Dementia: A Public Health Priority. Geneva: World Health Organization; 2012.

2. Alzheimer's Association, Thies W, Bleiler L. 2011 Alzheimer's disease facts and figures. Alzheimers Dement. 2011;7(2):208-244.

3. Alzheimer's Research Trust. Dementia 2010 The economic burden of dementia and associated research funding in the United Kingdom. Cambridge: Alzheimer's Research Trust; 2010.

4. World Health Organization. Neurological Disorders: Public Health Challenges. Geneva: WHO Press; 2007.

5. Seitz DP, Adunuri N, Gill SS, Gruneir A, Herrmann N, Rochon P. Antidepressants for agitation and psychosis in dementia. Cochrane Database Syst Rev. 2011;16;(2):CD008191.

6. Cusack BJ. Pharmacokinetics in older persons. Am J Geriatr Pharmacother. 2004;2(4):274-302.

7. Mangoni AA, Jackson SH. Age-related changes in pharmacokinetics and pharmacodynamics: basic principles and practical applications. $\mathrm{Br}$ J Clin Pharmacol. 2004;57(1):6-14.

8. Cherubini A, Del Signore S, Ouslander J, Semla T, Michel JP. Fighting against age discrimination in clinical trials. JAm Geriatr Soc. 2010;58(9):1791-1796.

9. Furu K, Wettermark B, Andersen M, Martikainen JE, Almarsdottir AB, Sørensen HT. The Nordic countries as a cohort for pharmacoepidemiological research. Basic Clin Pharmacol Toxicol. 2010;106(2):86-94.

10. Andersen TF, Madsen M, Jørgensen J, Mellemkjoer L, Olsen JH. The Danish National Hospital Register. A valuable source of data for modern health sciences. Dan Med Bull. 1999;46(3):263-268.

11. Official Statistics of Finland (OSF): Population projection. Helsinki: Statistics Finland. Available from: http://www.tilastokeskus.fi/til/vaenn/ index_en.html. Accessed on May 20, 2013.

12. Population structure [webpage on the Internet]. Helsinki: Statistics Finland. Available from: http://www.stat.fi/til/vaerak/index_en.html. Accessed May 20, 2013.

13. [Records and Information]. KELAN ATK-REKISTERIT JA NIIDEN SISÄLTÄMÄT TIEDOT REKISTEREITTÄIN. Available from: http:// uudistuva.kela.fi/in/internet/liite.nsf/net/310806125816mk/\$file/atk. pdf. Accessed July 2, 2013. Finnish

14. Religa D, Spångberg K, Wimo A, Edlund AK, Winblad B, EriksdotterJönhagen M. Dementia diagnosis differs in men and women and depends on age and dementia severity: data from SveDem, the Swedish Dementia Quality Registry. Dement Geriatr Cogn Disord. 2012;33(2-3): 90-95.

15. Suhonen J, Pirttilä T, Erkinjuntti T et al. pdate on current care guidelines. The diagnosis and medical treatment of memory disorders. Duodecim. 2010;126(18):2167-2168.

16. McKhann G, Drachman D, Folstein M, Katzman R, Price D, Stadlan EM. Clinical diagnosis of Alzheimer's disease: report of the NINCDSADRDA Work Group under the auspices of Department of Health and Human Services Task Force on Alzheimer's Disease. Neurology. 1984;34(7):939-944.

17. American Psychiatric Association. Diagnostic and Statistical Manual of Mental Disorders, 4th ed. Washington, DC: American Psychiatric Association; 1994.

18. Kela [homepage on the Internet]. Available from: http://www.kela.fi/ laake307. Accessed July 2, 2013. Finnish

19. Hujanen T, Peltola M, Häkkinen U, Pekurinen M. [Healthcare costs of men and women according to age groups in 2006]. Miesten ja Naisten Terveysmenot Ikäryhmittäin 2006. Report No: Stakesin Työpapereita 37/2008. Helsinki: Stakes; 2008. Finnish.

20. Hujanen T, Kapiainen S, Tuominen U, Pekurinen M. [Healthcare unit costs in Finland in 2006]. Terveydenhuollon Yksikkökustannukset Suomessa Vuonna 2006. Report No: Stakesin Työpapereita 3/2008. Helsinki: Stakes; 2008. Finnish.

21. Tiihonen J, Lönnqvist J, Wahlbeck K, et al. 11-year follow-up of mortality in patients with schizophrenia: a population-based cohort study (FIN11 study). Lancet. 2009;374(9690):620-627.
22. Purhonen M, Koponen H, Tiihonen J, Tanskanen A. Outcome of patients after market withdrawal of thioridazine: a retrospective analysis in a nationwide cohort. Pharmacoepidemiol Drug Saf. 2012;21(11): $1227-1231$.

23. Tiihonen J, Lönnqvist J, Wahlbeck K, Klaukka T, Tanskanen A, Haukka J. Antidepressants and the risk of suicide, attempted suicide, and overall mortality in a nationwide cohort. Arch Gen Psychiatry. 2006;63(12):1358-1367.

24. Finnish Cancer Registry [homepage on the Internet]. Available from: http://www.cancer.fi/syoparekisteri/en/. Accessed July 2, 2013.

25. [National Institute for Health and Welfare]. Kotihoidon asiakaslaskenta sosiaali- ja terveydenhuollossa 30.11. Available from: http://www.thl. fi/fi_FI/web/fi/tilastot/tietoa/rekisteriselosteet/kotihoidon_laskenta. Accessed July 2, 2013. Finnish.

26. Laitinen ML, Bell JS, Lavikainen P, Lönnroos E, Sulkava R, Hartikainen S. Nationwide study of antipsychotic use among community-dwelling persons with Alzheimer's disease in Finland. Int Psychogeriatr. 2011;23(10):1623-1631.

27. Bell JS, Lönnroos E, Koivisto AM, et al. Use of antiepileptic drugs among community-dwelling persons with Alzheimer's disease in Finland. J Alzheimers Dis. 2011;26(2):231-237.

28. Hommet C, Mondon K, Camus V, De Toffol B, Constans T. Epilepsy and dementia in the elderly. Dement Geriatr Cogn Disord. 2008;25(4): 293-300.

29. American Geriatrics Society Panel on Pharmacological Management of Persistent Pain in Older Persons. Pharmacological management of persistent pain in older persons. J Am Geriatr Soc. 2009;57(8): 1331-1346.

30. Han L, Agostini JV, Allore HG. Cumulative anticholinergic exposure is associated with poor memory and executive function in older men. J Am Geriatr Soc. 2008;56(12):2203-2210.

31. Künig G, Dätwyler S, Eschen A, Schreiter Gasser U. Unrecognised long-lasting tramadol-induced delirium in two elderly patients. A case report. Pharmacopsychiatry. 2006;39(5):194-199.

32. Brouquet A, Cudennec T, Benoist S, et al. Impaired mobility, ASA status and administration of tramadol are risk factors for postoperative delirium in patients aged 75 years or more after major abdominal surgery. Ann Surg. 2010;251(4):759-765.

33. Bell JS, Laitinen ML, Lavikainen P, Lönnroos E, Uosukainen H, Hartikainen S. Use of strong opioids among community-dwelling persons with and without Alzheimer's disease in Finland. Pain. 2011;152(3):543-547.

34. Lönnroos E, Kyyrönen P, Bell JS, van der Cammen TJ, Hartikainen S. Risk of death among persons with Alzheimer's disease: a national registerbased nested case-control study. J Alzheimers Dis. 2013;33(1):157-164.

35. Tolppanen AM, Lavikainen P, Solomon A, Kivipelto M, Soininen H, Hartikainen S. Incidence of stroke in people with Alzheimer disease: A national register-based approach. Neurology. 2013;80(4):353-358.

36. Tolppanen A, Lavikainen P, Soininen H, Hartikainen S. Incident hip fractures among community dwelling persons with Alzheimer's disease in a Finnish nationwide register-based cohort. PloS One. 2013;8(3): e59124.

37. Weller I, Schatzker J. Hip fractures and Alzheimer's disease in elderly institutionalized Canadians. Ann Epidemiol. 2004;14(5): 319-324.

38. Zhao Y, Shen L, Ji HF. Alzheimer's disease and risk of hip fracture: a meta-analysis study. Scientific WorldJournal. 2012;2012:872173.

39. Zhao Y, Kuo TC, Weir S, Kramer MS, Ash AS. Healthcare costs and utilization for Medicare beneficiaries with Alzheimer's. BMC Health Serv Res. 2008;8:108.

40. Baker NL, Cook MN, Arrighi HM, Bullock R. Hip fracture risk and subsequent mortality among Alzheimer's disease patients in the United Kingdom, 1988-2007. Age Ageing. 2011;40(1):49-54.

41. Trimpou P, Landin-Wilhelmsen K, Odén A, Rosengren A, Wilhelmsen L. Male risk factors for hip fracture-a 30-year follow-up study in 7,495 men. Osteoporos Int. 2010;21(3):409-416. 
42. Tolppanen AM, Lavikainen P, Solomon A, et al. History of medically treated diabetes and risk of Alzheimer disease in a nationwide casecontrol study. Diabetes Care. Epub January 22, 2013.

43. Profenno LA, Porsteinsson AP, Faraone SV. Meta-analysis of Alzheimer's disease risk with obesity, diabetes, and related disorders. Biol Psychiatry. 2010;67(6):505-512.

44. Gissler M, Shelley J. Quality of data on subsequent events in a routine Medical Birth Register. Med Inform Internet Med. 2002;27(1):33-38.

45. Isohanni M, Mäkikyrö T, Moring J, et al. A comparison of clinical and research DSM-III-R diagnoses of schizophrenia in a Finnish national birth cohort. Clinical and research diagnoses of schizophrenia. Soc Psychiatry Psychiatr Epidemiol. 1997;32(5):303-308.

46. Teppo L, Pukkala E, Lehtonen M. Data quality and quality control of a population-based cancer registry. Experience in Finland. Acta Oncol. 1994;33(4):365-369.

47. Tolonen H, Salomaa V, Torppa J, Sivenius J, Immonen-Räihä P, Lehtonen A; FINSTROKE register. The validation of the Finnish Hospital Discharge Register and Causes of Death Register data on stroke diagnoses. Eur J Cardiovasc Prev Rehabil. 2007;14(3):380-385.

48. Meretoja A, Kaste M, Roine RO, et al. Trends in treatment and outcome of stroke patients in Finland from 1999 to 2007. PERFECT Stroke, a nationwide register study. Ann Med. 2011;43 Suppl 1:S22-S30.

49. Sund R, Nurmi-Lüthje I, Lüthje P, Tanninen S, Narinen A, Keskimäki I. Comparing properties of audit data and routinely collected register data in case of performance assessment of hip fracture treatment in Finland. Methods Inf Med. 2007;46(5):558-566.
50. Mähönen M, Salomaa V, Torppa J, et al. The validity of the routine mortality statistics on coronary heart disease in Finland: comparison with the FINMONICA MI register data for the years 1983-1992. Finnish multinational MONItoring of trends and determinants in CArdiovascular disease. J Clin Epidemiol. 1999;52(2):157-166.

51. Pajunen P, Koukkunen H, Ketonen M, et al. The validity of the Finnish Hospital Discharge Register and Causes of Death Register data on coronary heart disease. Eur J Cardiovasc Prev Rehabil. 2005;12(2): 132-137.

52. Rapola JM, Virtamo J, Korhonen P, et al. Validity of diagnoses of major coronary events in national registers of hospital diagnoses and deaths in Finland. Eur J Epidemiol. 1997;13(2):133-138.

53. Sund R. Quality of the Finnish Hospital Discharge Register: a systematic review. Scand J Public Health. 2012;40(6):505-515.

54. Haukka J, Suvisaari J, Tuulio-Henriksson A, Lönnqvist J. High concordance between self-reported medication and official prescription database information. Eur J Clin Pharmacol. 2007;63(11):1069-1074.

55. Rikala M, Hartikainen S, Sulkava R, Korhonen MJ. Validity of the Finnish Prescription Register for measuring psychotropic drug exposures among elderly finns: a population-based intervention study. Drugs Aging. 2010;27(4):337-349.
Clinical Epidemiology

\section{Publish your work in this journal}

Clinical Epidemiology is an international, peer-reviewed, open access journal focusing on disease and drug epidemiology, identification of risk factors and screening procedures to develop optimal preventative initiatives and programs. Specific topics include: diagnosis, prognosis, treatment, screening, prevention, risk factor modification, systematic

\section{Dovepress}

reviews, risk \& safety of medical interventions, epidemiology \& biostatical methods, evaluation of guidelines, translational medicine, health policies \& economic evaluations. The manuscript management system is completely online and includes a very quick and fair peer-review system, which is all easy to use. 